\title{
About a Role and Value of Nonverbal Communication in Psycholinguistics
}

\author{
Ilhan Yildirim ${ }^{1}$, Zeine Orazbekova ${ }^{1} \&$ Yener Unal $^{1}$ \\ ${ }^{1}$ Faculty of Philology and Educational Sciences, Suleyman Demirel University, Kazakhstan \\ Correspondence: Ilhan Yildirim, Faculty of Philology and Educational Sciences, Suleyman Demirel University, \\ 040900, 1/1, St. Abylaikhan, Kaskelen, Almaty, Kazakhstan. Tel: 77-07-733-3501. E-mail: ilhan195@gmail.com
}

Received: August 27, 2013

Accepted: December 24, 2013 Online Published: January 26, 2014

doi:10.5539/ass.v10n4p27

URL: http://dx.doi.org/10.5539/ass.v10n4p27

\begin{abstract}
Since the late 1970s, the problems of psycholinguistics were influenced by the state of affairs in linguistics and related sciences. This is primarily a complex of sciences about the nature and dynamics of cognitive processes. For most American and English-speaking psycholinguists N. Chomsky's theory of generative grammar as a reference to the language science is the most influential. They try to verify the extent of psychological hypotheses based on Chomsky's theory corresponding to the observed behavior. From this perspective, some authors consider the child's speech, the other-the role of language in social interactions, and others-the relationship of language and cognitive processes. The aim of our study is to determine and describe the characteristic and distinguishing features of non-verbal communication of Turkic culture and compare the data and if possible give them an interpretation.
\end{abstract}

Keywords: psycholinguistics, linguistics, non-verbal communication

\section{Introduction}

The globalization of the world's cultural process, mass migration and interpenetration of different languages and cultures (multiculturalism), the emergence of global computer networks-these factors have given particular weight to study the processes and mechanisms of mastering a foreign language. This greatly expanded the understanding of the areas of knowledge and research interests which overlap with psycholinguistics. This science is rapidly developing. The term "psycholinguistics" entered the academic community since 1954, after publishing CH. Osgood and T. Sebeka's article in the USA. But the ideas that are close to the problems of psycholinguistics, emerged and developed much earlier. It can be assumed that the psycholinguistic perspective of language learning actually existed long before the term "psycholinguistics" was coined by a group of American scientists.

Since the late 1970s, the problems of psycholinguistics were influenced by the state of affairs in linguistics and related sciences. This is primarily a complex of sciences about the nature and dynamics of cognitive processes. For most American and English-speaking psycholinguists N. Chomsky's theory of generative grammar as a reference to the language science is the most influential. They try to verify the extent of psychological hypotheses based on Chomsky's theory corresponding to the observed behavior. From this perspective, some authors consider the child's speech, the other-the role of language in social interactions, and others-the relationship of language and cognitive processes. Developed on the different basis, psycholinguistics has acquired its interest in the person as a native speaker and a tendency to regard language as a dynamic system of speech (verbal behavior). According to many scholars, psycholinguistics has not yet become a science with clearly defined boundaries.

Psycholinguistics initially focused on the study of real processes of speaking and understanding "human language". The variety of language functions in society and its close ties with human mental activity makes interaction of linguistics and the relevant social and psychological sciences very flexible.

Application tasks were the factors to separate psycholinguistics as an independent research area. Psycholinguistics should not be regarded as a kind of linguistics or psychology. This is a complex science that relates to linguistics and psychology as well. Psycholinguistics primarily inherited their methods of investigation from psychology. Experimenting, method of linguistic experiments, observation and self-observation are 
frequently used as methods of Psycholinguistics investigation. The main trends in the development of modern linguistics are quite comparable with psycholinguistics trends. The concept of language has been changed. Earlier in the center of linguists' interest were linguistic resources (phonetic, grammatical, lexical), now it is clearly recognized that all of these language features are only formal tools in the process of communication. Thus, concepts of linguistics are increasingly becoming major. In recent decades Linguistics pays more attention to the study of the text. And psycholinguistics is interested in the texts of their specific structure, and functional specialization. It constantly interacts with sociolinguistics, applied linguistics Ethno linguistics and computer linguistics.

The aim of this study is to determine and describe the characteristic and distinguishing features of non-verbal communication of Turkic culture and compare the data and if possible give them an interpretation.

In modern linguistics, the study focused on the relationship of language and identity in the culture, the study of the emotional state, expressed through non-verbal means, namely, through facial expressions and gestures is important and interesting. At present, interest in the study of gestures and facial expressions increases (Stepanov \& Konetskaya, 1997; Bazhenova, 2001; Papulinova, 2003; Kreydlin, 2004, 2005, 2010; Kovalev, 2012).

Any information transference is possible only by means of signs, and symbolic systems. There are a number of sign systems used in the communication process. Verbal and non-verbal communication use different sign systems. Non-verbal type of communication as a language of gestures is area which recently becomes a focus of researches. Non-verbal communication includes the following sign systems: the optical-kinetic, Para-and extra linguistic, space and time perception in the communication process, eye contact. The combination of these tools performs the following functions: speech addition, speech replacement for emotional representation in communicative process. All of these additions increase meaningful information semantically, but not through the inclusion of additional speech techniques. The organization of space and time in the communication process also serves as a special meaningful component. For example, placing partners face each other contributes to the contact symbol and attention to the speaker, while the shout in the back may also have some negative impact. Some spatial forms of space organization are experimentally proved to be effective in the communicative process. In various subcultures some standards regarding timing are developed and serve as a type of semantically meaningful information. In time arrival for the diplomatic negotiations symbolizes politeness, on the contrary, being late is interpreted as a sign of disrespect. In the case of human communication proposed a special method of estimating the intimacy of communication based on the study of the spaces organization. For example, Hall recorded the norm approximation between the partners in dialogue, characterizing American culture: the intimate distance $(0-45 \mathrm{~cm})$, personal distance $(45-125 \mathrm{~cm})$ and social distance $(120-400 \mathrm{~cm})$, a public distance $(400-750 \mathrm{~cm})$. These studies are of great practical importance, especially in the analysis of the successful group discussions.

The specific symbol system used in the communication process is "eye contact", which takes important place in the visual communication. Research in this area is closely related to general psychological research of visual perception-eye movements. The exchange frequency of eye contact, their duration, and static and dynamic change, the eye contact avoidance are examined in the socio-psychology. Like all non-verbal means, eye contact is important aspect of non-verbal communication indicating the readiness to support the communication and encourages partners to continue the dialogue or vice versa.

For all four systems of non-verbal communication raises a general methodological question. Each culture uses its own system of signs that can be considered as a specific code. Any information should be coded in such a way that all the participants of the communication process to be familiar with the system of codification and decoding. Speech coding system is well known, more or less, but in the case of non-verbal communication it is important to determine what can be considered as a code. Most important is how to ensure that the other partner in dialogue owned the same code system. Otherwise there will not be any additional information in the process of communication.

\section{Method}

K. Berdvistl offered to highlight a unit of human body movement. The main argument is based on the experience of structural linguistics: Movements are divided into units then these units are formed of more complex structures. The set of units is a kind of gestures alphabet. Some sort of body language dictionaries were built on the Berdvistla's proposals. More local in nature are proposals to build a gesture vocabulary. We have a certain catalog of gestures in different national cultures to be described. The Berdvistla's proposals contained the following aspect; the entire human body has been divided into 8 areas: face, head, right arm, left arm, right leg, left leg and upper body, and the lower part of the body as a whole. The meaning of the dictionary is to connect 
the units "kins" to specific part of body, to "write" gestures that give certain uniqueness and will execute the code function. However, this method of recording is not quite reliable. Generally, in the literature there are more than 20,000 descriptions of facial expressions. In order to classify them P. Ekmanom's FAST-Facial Affect Scoring Technique is used. Principles of the technique: The face is divided into three zones of horizontal lines (the eyes and forehead, nose, mouth and chin). Six basic emotions most often expressed by facial means are joy, anger, surprise, disgust, fear, sadness. Fixation emotional zone allows you to register facial movements more or less certain. This technique is popular in medicine practice. There are a number of attempts to use it in normal everyday situations. All of the described system of non-verbal communication plays an important supporting role in the communication process. Non-verbal communication systems help to identify a significant parameter of the communication process, as the intentions of the participants. Along with verbal communication system, these systems provide the exchange of information, which is necessary to organize joint activities. Different characteristics can be identified in the behavior of people from different cultures that represent a relatively stable continuum (behavioral universals) to highly specific, or culturally-specific. Among the universals of negatine basis, include the expressive movements of crying, laughter, smiles, expressions of sadness and pain. In most cases, however, similarity of behavioral strategies is due to the similarities of cultural needs. The degree of control over the non-verbal behavior may also be a cultural-specific indicator. Among the cultures, strictly regulating feeling expression is the Japanese culture (Pronnikov, 1985). Although children are taught from childhood to hide their feelings and negative emotions in all forms, the emphasis is mainly done on facial expressions. The Japanese have mastered to control facial expressions, but hands at times betray their true condition. In one of the short stories titled "Handkerchief", R. Akutagawa tells the story of a woman who lost her son, and had come to inform his university professor (Akutagawa, 2000). The woman's face radiated calmness with a weak smile but woman's hands, desperately crumpling handkerchief testified her unbearable pain. Arab culture and the culture of the Mediterranean (Italian, Spanish) are characterized by exceptional facial expressions. In these cultures feelings are usually not hidden. People may laugh out loud or cry in public, and that won't seem indecent.

Character's body movements in a variety of his mental states, actions, reactions, characteristics contribute to a better disclosure of the internal world of the hero, his understanding of the world and enable us to give an aesthetic appreciation of his behavior and values. Body language can inadvertently reveal what the character carefully hides. Episodes of non-verbal means of communication in M. Auezov "Abai's Way" can define their role in the character inner world portrayal and the author's intent. From this point of view, gestures may carry aesthetic value that will be mapped to a certain standard of behavior accepted in a given period of time and space. In our work, we divide all movements to voluntary (natural) and involuntary (motivated). Movements help to penetrate into the unconscious, involuntary movements and may explain the motivation of behavior and actions. As Kovalev I. observes, body language improves the accuracy, reliability, visibility, the effect of reality portrayed. Kreydlin E, who has studied the body language, proposed the following classification of communicative gestures: general, and etiquette. Analysis of Auezov's novel "Abai's Way" showed that the author makes extensive use of gestural kinesics to describe the characters. More than 500 contexts with different gestures are discovered in the novel. The characters of the novel, are, as a rule, collective images (Kunanbay, Zhirenshe, Ulzhan, Zera, Ospan, Abay, etc.) and manifested in behavior patterns and norms relevant to their social status and time. A detailed novel analysis allowed finding examples of non-standard gestural kinesics operations. Thus, describing the character life in the novel, the author uses common gestures. For example, Ulzhan behaves as a weak woman, seeking Abay's protection. This natural gesture shows the essence of woman's defenseless, it cannot be more eloquently expressed. The author emphasizes the tragedy of Ulzhan's situation. This woman's gesture was intended to arouse pity for her inner feelings. However, the reader feels the author's position, the writer introduces the word "grim" and "deep" to produce Abai's exact nature and becomes an artistic portrait causing the desired feeling in the reader. Zera cured her sick grandson Abay with ancient treatment. It is a universal and a real gesture in these conditions, when grandmother treats her beloved grandson. But it also shows that Zera truly loved her grandson. Auezov describes the general communicative gestures, using the gender approach. Even a small number of examples analyzed manifest features of writer's individual skill and the role of movements in the text. They are so naturally fit into the story that the reader hardly notices them. However, the writer has resorted to a number of additional details and enters them into the text purposely, so that the readers can notice these gestures. To produce the same effect the writer uses different syntax. For instance ... turning Abay's face to the setting sun, she continued her amazing treatment ... This friendly gesture adopted by many Eastern cultures, in this context, has the tone of ritualism. Zera-a typical representative of the ethnic era: intelligent, caring, clever, wise and loving grandmother. Ritual treatment of grandson disease contributes to the formation of a new connotation gesture. At first glance, gestures appear to be similar, but expressed by different means their semantic content is differentiated and often associated with strong feelings 
and emotions. Described gesture shows the desperation and helplessness before diseases and gives the intensity. In this context different non-verbal means focuses on transmission of human emotions and relationships. Zera's love and anxiety are transmitted through such emotional reactions as tears and kisses, etc. Mulla with his hand on the Koran (the gesture of the great oath also refers to the universal gesture) blesses Abay. The reader understands the importance of this gesture. M. Auezov, being a realist writer, supplies his heroes with characteristics and reactions common in human society. Interesting is the description of gestures associated with the expression of strong emotions such as anger, fear. Flagrant manifestation of Kunanbai's anger is the gesture characterizing him as a strong man: Kunanbay stepped aside and yanked down his hand, made a sign who stood on the top "drop him!" This gesture displays man's flatness, as well as the criticism of forbidden relationships. It gives the impression of event irreversibility, the failed hopes and enhances the effect of character's anger. His eyes were bloodshot. Pale face darkened. His fingers clenched into a fist. This natural gesture shows the essence of man, which cannot be expressed more eloquently, and clearly emphasizes the tragedy of the character's position.

\section{Results}

According to our findings, M. Auezov's novel has a wide range of movements, reflecting man's relation to all sorts of reality, including, social and family relationships in a society that identify their role and importance in the text. At the same time, it allows to establish the compliance with the rules and principles applicable in a certain period of time and space for a certain group of people or an individual. Gestural kinesics in M. Auezov's novel provide valuable material on writer's artistic method, his personality and skill can detect intensity, emotion, imagery in the aesthetic evaluation of body language. Movements in the novel come into complex relationships with the idea of the work, with the images, characters, views, helping to realize the deeper vision of writer's world.

\section{Discussion}

Cultures can vary in strength, and emotional displays on the threshold of emotional signals perception, but the type of emotions and their outward manifestation are universal. The ability to identify basic human emotions is also universal. These data point to the fundamental importance of non-verbal communication in human life. The conclusions are as follows: the languages should be studied in unity with the world and culture of the people who speak those languages. Its effectiveness, in addition to knowledge of the language depends on many factors: the conditions and culture of communication, knowledge of non-verbal forms of expression (facial expressions, gestures). Overcoming the language barrier is not enough to ensure effective communication between people of different cultures. You need to overcome cultural barriers. In cross-cultural communication it is necessary to recognize the features of the national character, their emotional system, and the national thinking specifics. There is a need for more complete study of the world (not language, and the world) the speakers, their culture in a wide ethnographic sense, their lifestyle and the national character, mentality because the real use of words in speech largely determined by knowledge of speakers' social and cultural life, the community language. Socio-cultural structures are at the heart of the national structures. The knowledge of words and grammar rules is not enough. You need to know the world of the target language as much as possible. That is why special attention is paid to the study of the "world of studied language" Such an attempt is especially important now, when languages and cultures are penetrating fast and we faced the problem of promoting tolerance for other cultures, awakening interest in and respect them, to overcome a feeling of irritation, failure, or simply being different from other cultures. It is the factor caused everyone's attention to the issues of cross-cultural and international communication.

\section{References}

Auezov, M. (1977). Abay's way. Novel, I. Almaty.

Butovskaya, M. L. (2000). The evolution of human behaviour: The relationship between the biological and the social. Anthropology, XXXVIII(2), 169-180.

Kovalev, I. B. (2012). Communicative hand gestures. Vestnik, 1, 115-118.

Kreidlin, G. E. (2000). Nonverbal semiotics: The body and natural languages. Moscow.

Lisina, M. I. (n. d.). Problems of ontogenesis of communication, 144.

\section{Copyrights}

Copyright for this article is retained by the author(s), with first publication rights granted to the journal.

This is an open-access article distributed under the terms and conditions of the Creative Commons Attribution license (http://creativecommons.org/licenses/by/3.0/). 